Rev. Adm. Saúde - Vol. 18, № 70, jan. - mar. 2018

http://dx.doi.org/10.23973/ras.70.79

RELATO DE CASO

\title{
Normas sobre construção de estabelecimentos assistenciais de saúde no Brasil e a enfermagem
}

Rules on health assistance facilities construction in Brazil and nursing abstract

\author{
Patricia Bover Draganov ${ }^{1}$, Maria Cristina Sanna ${ }^{2}$
}

1. Enfermeira e arquiteta, mestre em ciências. Membro do Grupo de Estudos e Pesquisa em Administração em Saúde e Gerenciamento em Enfermagem (GEPAG) da Escola Paulista de Enfermagem da Universidade Federal de São Paulo (EPE-UNIFESP), São Paulo SP

2. Enfermeira, doutora em enfermagem. Pesquisadora independente. Pesquisadora do GEPAG da EPE-UNIFESP, São Paulo SP

\section{RESUMO}

Introdução: A Resolução de Diretoria Colegiada ANVISA no 50 (RDC50), regulamenta a construção de estabelecimentos assistenciais de saúde (EAS) desde 2002, porém houve versões anteriores. Objetivo: Descrever as transformações ocorridas nas normas de construção de EAS, de 1974 a 2002, considerando a enfermagem. Método: Estudo histórico documental, sobre as legislações de espaços físicos de EAS no Brasil. Resultados: A primeira norma sobre a construção do hospital geral, de 1974, teve enfermeiras como protagonistas. Em 1977 vigorou Portaria no 400, com ênfase nas áreas de atendimento, tendo a enfermagem destaque. Em 1995, surgiu a Portaria no 1884. O "posto de enfermagem", passou a ser destinado também a médicos e os consultórios foram designados como indiferenciados. A Constituição Federal e a Política HumanizaSUS influenciaram a RDC50, consolidando a multiprofissionalidade. Conclusão: As normas para a construção de EAS afetaram a distribuição espacial para acomodar o trabalho multiprofissional, com perda de espaços antes destinados à enfermagem

Palavras-chave: arquitetura; edifícios de saúde; legislação hospitalar; enfermagem 


\begin{abstract}
Introduction: The Resolution of the Collegiate Board of Directors ANVISA no.50 (RCD50), regulates the construction of health care establishment (HCE) since 2002, but there were previous versions. Objective: To describe the transformations that occurred in the EAS construction standards, from 1974 to 2002, considering nursing. Method: Historical documentary study on the laws of physical spaces of HCE in Brazil. Results: The first standard on the construction of general hospital, 1974, had nurses as protagonists. In 1977, Ordinance 400 was in force with emphasis in the service areas, with nursing highlighted. In 1995, the 1884 Ordinance appeared. The "nursing station" was also destined for doctors and the offices were designated as undifferentiated. The Federal Constitution and the HumanizaSUS Policy influenced the RCD50, consolidating multiprofessionality. Conclusion: The norms for the construction of HCE affected the spatial distribution to accommodate the multiprofessional work, with loss of spaces previously destined to nursing
\end{abstract}

Keywords: architecture; health buildings; hospital law; nursing

\title{
INTRODUÇÃO
}

No Brasil há um sistema de ordenamento de leis que distribui hierarquicamente todo o sistema jurídico; esse ordenamento é denominado sistema normativo. $\mathrm{O}$ sistema normativo tem, como máxima, a Constituição Federal de 1988 e, no campo da saúde e de arquitetura de estabelecimentos assistenciais de saúde (EAS), segue-se hierarquicamente, em posições decrescentes, respectivamente, as leis orgânicas da saúde, a Resolução da Diretoria Colegiada no 50 (RDC50), os planos diretores regional e locais de estados e municípios, o código de obras, as normas brasileiras e os planos de EAS, nos quais se inserem os projetos arquitetônicos (Bonavides, 2012).

Esse conjunto de normas jurídicas têm o papel de orientar os sujeitos de direito sobre direitos e obrigações. Tais normas são desenvolvidas pelo poder legislativo, que elabora leis; poder executivo, que elabora decretos, medidas provisórias ou regulamentares; e órgãos ou empresas como, por exemplo, a Agência Nacional de Vigilância Sanitária (ANVISA), que elabora estatutos, regulamentos e resoluções, entre outros. A RDC50 (Brasil, 2002), por exemplo, é uma norma jurídica regulamentadora que foi aprovada pela diretoria colegiada da ANVISA para orientar a construção, reforma e ampliação de EAS. 
A RDC50, componente do objeto de estudo desta pesquisa, é a norma mandamental em vigor que regulamenta as condições técnicas que devem ser respeitadas no planejamento, projeto e construção de EAS (Brasil, 2002).

Assim, atualmente, quaisquer atividades arquitetônicas aplicadas a EAS devem obedecer ao dispositivo legal - RDC50, mas nem sempre foi assim. Antes de 21 de fevereiro de 2002, quando a RDC50 foi aprovada, outras normas eram vigentes, sendo a primeira específica datada de 1974, denominada "Normas de Construção e Instalação do Hospital Geral” (Brasil, 1974a). Para compreender o contexto no qual a referida norma se inseria, foi necessário buscar essa história, na qual a enfermagem teve papel relevante.

A enfermagem reúne profissionais que estão intrinsecamente relacionados aos EAS, pois esses são locais em que seus profissionais exercem suas atividades laborais, desenvolvidas em um espaço físico que compartilha com outros atores que compõem esse cenário, ou seja, auxiliares e técnicos de enfermagem, fisioterapeutas, médicos e nutricionistas, entre outros.

Enfermeiros aprendem conteúdos sobre gerenciamento de recursos físicos há muito tempo. Na década de 1970, ocorreu a terceira reforma curricular na formação de enfermeiros, aprovada pelo Parecer MEC no 163/72, que prescreveu que a formação enfermeiros particularmente deveria voltar-se para a administração de serviços de enfermagem nas áreas de saúde pública, materno-infantil e hospitalar (Brasil, 1974b). Na mesma década, a enfermeira Clarice Della Torre Ferrarini foi uma das profissionais da saúde a compor a equipe que elaborou o documento Normas de Construção de Hospitais e Padrões Mínimos de Assistência de Enfermagem, que era composto de um rol de terminologias técnicas para favorecer a comunicação entre os atores que compunham o cenário da saúde naquela época (Sanna, 2002). Essa participação sugere que enfermeiros, naquela ocasião, ocupavam cargos administrativos de alto escalão e estavam envolvidos em decisões estratégicas, como a enfermeira citada acima.

Nota: Clarice Della Torre Ferrarini foi enfermeira formada em 1943 pela escola Anna Nery e especialista em administração hospitalar nos EUA. Trabalhou no Hospital das Clínicas de São Paulo gerenciando o serviço de enfermagem por mais de 20 anos, participou da criação do Conselho Federal e Regional de Enfermagem e foi presidente da Associação Brasileira de Enfermagem e dirigiu a divisão nacional de organização do Ministério da Saúde da década de 1970. Em 1976 recebeu o prêmio mulher do ano. BERTONI, E. Pioneira da enfermagem no País. Folha de S. Paulo, São Paulo, 18 jan. 2012. Folha Cotidiano. Disponível em: http://www1.folha.uol.com.br/cotidiano/1035785-clarice-della-torre-ferrarini-1921-2012--pioneira-da-enfermagem-no-pais.shtml, Acesso em 26 de jul. 2017

Na década de 1980, a enfermagem iniciou um processo de renovação mediada pelo "saber científico". O ensino de conteúdos sobre administração em enfermagem, nesse contexto, foi um "espaço" para profundas discussões e debates sobre processos de trabalho e quebra de paradigmas (Formiga, 2005). Em 1986, a Lei no7498, ainda em vigor, regulamentou o exercício profissional da enfermagem, definindo, em seu art. 11, inc. II, "d" (Brasil, 1986), que "o 
enfermeiro exerce todas as atividades de enfermagem, cabendo-Ihe [...]: II como integrante da equipe de saúde, [...]: d) a participação em projetos de construção ou reforma de unidades de internação".

Posteriormente, em 1994, a Portaria MEC no 1721 definiu a Quarta Reforma Curricular da formação de enfermeiros, dando destaque para o conteúdo de administração de serviços de enfermagem, pois nesse currículo, $15 \%$ da carga horária total, ou seja, 525 horas, pelo menos, seriam obrigatoriamente destinadas a esse conteúdo (Brasil, 1994a).

Em 2001, a Quinta Reforma Curricular na formação de enfermeiros, ocorrida com a aprovação da Resolução MEC no 3, posicionou o enfermeiro como gestor e líder de equipes de saúde (Brasil, 2000), o que foi reforçado em 2008, com o Parecer no 213 (Brasil, 2008), que prescreveu o aumento da duração do curso e de sua carga horária total. Nessa norma há declaração expressa de que enfermeiros coordenam equipes multiprofissionais no Sistema Único de Saúde (SUS) e, portanto, devem ter habilidades de gestão, o que inclui a gestão de recursos físicos, dentre outras.

Diante da necessidade de o enfermeiro desenvolver competências na gestão de recursos físicos, justamente pela demanda profissional construída ao longo do tempo e compreendendo que essas competências corroboram com a compreensão das transformações espaciais de EAS e o posicionamento da enfermagem nesse contexto, questiona-se: Quais foram as transformações ocorridas nas normas de construção de EAS, de 1974 a 2002, e qual foi o posicionamento espacial da enfermagem nesse período? É certo que houve movimentação da enfermagem nesse cenário e que isso implicou em disputa de espaços nos EAS. Nessa perspectiva, justifica-se a realização deste estudo, pela contribuição que este possa dar para a compreensão da trajetória das transformações ocorrida nos EAS e sua influência no trabalho do enfermeiro.

Em um estudo bibliométrico (Draganov et al, 2014) notou-se que a enfermagem se envolveu pouco com a temática gestão de recursos físicos, pelo menos no nível acadêmico. Frente a isso, notou-se que há carência de produtos que tragam o olhar desse profissional sobre o tema e lhe permitam estabelecer discussões acerca da gestão de recursos físicos e da distribuição desses espaços que certamente refletiram e influenciaram a qualidade da assistência prestada nos EAS no Brasil.

\section{OBJETIVO}

Descrever as transformações ocorridas nas normas de construção de EAS, de 1974 a 2002, considerando os espaços físicos utilizados pela enfermagem nesse período.

\section{MATERIAL E MÉTODOS}


Estudo de natureza histórica sobre a legislação que envolve a regulamentação de construção de EAS no Brasil, considerando o posicionamento espacial da enfermagem nesse contexto. Para este estudo será utilizada a metodologia histórica, que é útil para responder às indagações sobre causa, efeito e tendência, com base em acontecimentos passados e, assim, esclarecer comportamentos e práticas atuais (Polit, 2004).

Para a execução do estudo foi utilizada a análise documental e a abordagem histórica. A análise documental percorre etapas que têm, como propósito, estudar e compreender documentos de forma a relacioná-los com circunstâncias sociais e econômicas que envolveram o fato. O método histórico utiliza-se de documentos para investigar fatos sociais e suas relações com o tempo sociocultural e temporal (Richardson, 1999). Assim, os documentos são muito mais que fontes de informação contextualizadas, ou seja, fornecem informações sobre determinados assuntos em estudo dentro de contextos sócio, político e cultural de uma determinada época (Lüdke e André, 1999).

A pesquisa histórica apresenta dois objetivos fundamentais: narrar o passado por meio de coleta e descrição de fatos que ocorreram em determinado momento (corte transversal) e a descrição dos fatos através do tempo (estudo longitudinal). Dessa forma, utilizou-se o estudo do tipo longitudinal por ser o ideal para alcançar o objetivo deste estudo. (Lüdke, 1986)

O recorte temporal utilizado teve seu marco inicial assinalado no ano de concepção da primeira publicação oficial sobre "Normas de Construção e Instalação do Hospital Geral" elaborada em 1974, e o final em 2002, com a última versão publicada da Resolução de Diretoria Colegiada RDC no 50/2002.

Como fontes, foram utilizadas as normas e manuais de projetos para EAS, ou seja, a documentação que informa sobre as transformações legais que subsidiaram a construção, reforma ou ampliação de EAS, mais especificamente, as normas de âmbito nacional que antecederam a RDC50 e ela própria.

Para a coleta de dados, os documentos que contêm os registros referentes às normas de construção de EAS foram copiados de acervo pessoal ou consultados em sítios públicos, durante a coleta de dados. Foi elaborado um sistema de armazenamento/identificação de dados e catalogação destes por meio de planilha Excel $\AA$, utilizando-se um número de série para cada documento.

Para análise dos documentos encontrados, foi efetuada a ordenação por datas e leitura compreensiva e a elaboração de mapas conceituais, que são estruturas gráficas esquemáticas do tipo organogramas detalhados que permite, construir, organizar e representar o conhecimento (Tavares, 2007). Após, realizou-se e o agrupamento de itens de conteúdo por convergência temática, observando-se data, origem, conteúdo e relação com o objeto de estudo.

Os achados foram, então, descritos e interpretados à luz da literatura científica encontrada sobre o tema, para responder ao objetivo deste estudo. 


\section{RESULTADOS}

A história das normas para a construção de EAS teve seu início no ano de 1974, com o documento de título "Normas de Construção e Instalações do Hospital Geral" (Brasil, 1974a). A referida norma foi estabelecida pela Coordenação de Assistência Médica e Hospitalar do Ministério da Saúde para assegurar que programação, projeto, construção e instalação adequados favorecessem o atendimento eficiente, seguro e econômico no hospital geral. $O$ documento continha requisitos mínimos para planejamento, construção, reforma ou ampliação de hospital do tipo geral de qualquer capacidade, excluindo, portanto, hospitais de longa permanência, como psiquiátricos, geriátricos e de especialidades (Brasil, 1974a).

Dentre os consultores, que envolviam um coordenador, dez engenheiros, quatro arquitetos, quatro enfermeiros, seis médicos, quatro desenhistas, um administrador, uma nutricionista e um técnico projetista, selecionados pelo órgão governamental para a elaboração dessa norma, estava a enfermeira, livre-docente da Escola de Enfermagem da Universidade de São Paulo (USP) e, na época, presidente da Associação Brasileira de Enfermagem, seção São Paulo, Dra. Circe Mello Ribeiro. Também integrava a equipe de trabalho a enfermeira Maria Consuelo Borges Matos, chefe do serviço de enfermagem do Hospital Infantil Darcy Vargas de São Paulo, a enfermeira Ondina Teixeira, também farmacêutica e consultora de planejamento hospitalar e o enfermeiro Orlando Fabbri Neto, diretor do Serviço de Enfermagem da Clínica Psiquiátrica do Hospital das Clínicas da FMUSP. A presença marcante de enfermeiros na construção de documento de tamanha relevância, como a Norma de Construção e Instalação do Hospital Geral, sugeria que suas atribuições envolviam decisões estratégicas de caráter abrangente e político, participando, portanto, da elite administrativa dessas instituições.

A norma produzida em 1974, que pode ser apreciada como um todo na Figura 1, era estruturada nos capítulos: disposições preliminares, localização, acessos e circulação e programas funcionais mínimos, com a descrição detalhada das unidades de internação, centro cirúrgico e obstétrico, ambulatório, laboratórios diversos, radiologia, necrotério, administração e lavanderia, entre outras áreas. No item programas funcionais que os espaços foram descritos em termos de quem o ocupava e o quanto seria ocupado. O conteúdo de cada área não citava especificamente "espaços" da enfermagem, mas utilizava os termos: posto, sala de serviço e consultórios, sendo que, em alguns deles, por vezes, era citado que era destinado ao enfermeiro e médico, para executarem a assistência à saúde. No item sobre administração, era previsto espaço para a enfermeira-chefe sendo a norma clara quanto à necessidade dessa profissional ter espaço privativo na área administrativa (Brasil, 1974a). 


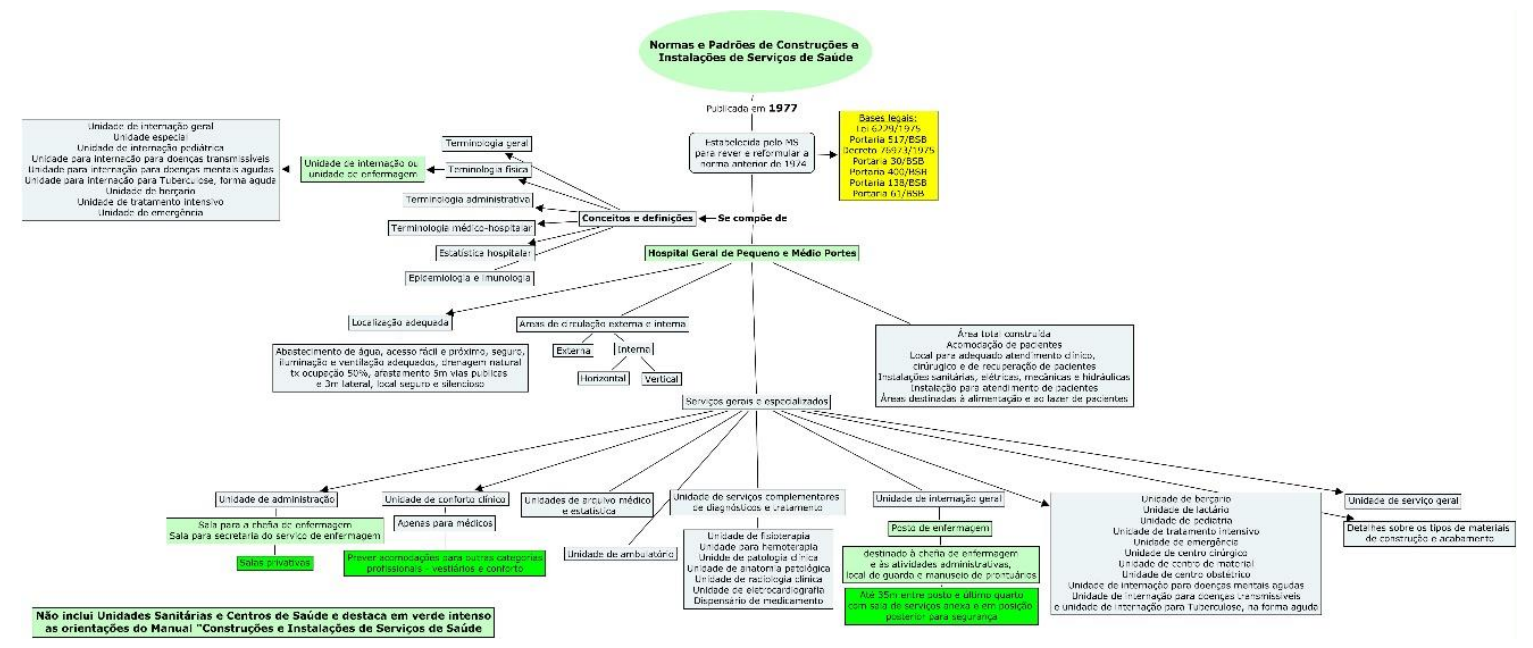

Figura 1. Normas de construção e instalações do hospital geral

Em 1977, fundamentada na lei no 6229 de 17 de julho de 1975, que dispunha sobre a organização do Sistema Nacional de Saúde, um grupo de trabalho composto de 11 médicos, três arquitetos e uma enfermeira, constituído pela Portaria no 517/BSB, do Ministério da Saúde, estudou, revisou e reformulou as publicações "Normas de Construção e Instalações do Hospital Geral", "Normas de Administração e Controle do Hospital" e "Avaliação do Hospital", desenvolvendo o documento de título: Normas e Padrões de Construção e Instalação de Serviços de Saúde (Brasil, 1977). Outra Portaria, de no 30/BSB, de 11 de fevereiro de 1977, aprovou "Conceitos e Definições" de que tratava o item I, do Decreto o 76.973, referente a essas normas e padrões. As Portarias no 400/BSB e no 138/BSB complementavam o disciplinamento da matéria de que tratavam os itens II a XIV, do referido decreto. Assim, essa norma (Brasil, 1977) foi estruturada contendo três partes, que podem ser apreciadas na Figura 2.

A primeira parte, denominada $A$, apresentava conceitos e definições de terminologia empregada na descrição de recursos físicos. Esses elementos eram classificados em geral, física, administrativa, médico-hospitalar; estatística hospitalar, medidas e indicadores; e epidemiologia e imunologia. No que se referia à terminologia física, a enfermagem era citada no termo unidade de internação, que poderia também ser denominada como unidade de enfermagem, definida por "conjunto de elementos destinados à acomodação do paciente internado", e que englobava "facilidades adequadas à prestação de cuidados necessários a um bom atendimento". Essa unidade era dividida em internação geral, especial, pediátrica, de doenças transmissíveis, de doenças mentais agudas, para tuberculose na forma aguda, berçário, de tratamento intensivo e emergencial.

A segunda parte da norma, denominada $B$, discursava sobre construção, reforma e ampliação, contendo orientações sobre localização, circulação interna e externa, área total construída, acomodação de pacientes, locais de atendimento clínico, cirúrgico e de recuperação de pacientes, instalações sanitárias, elétricas, mecânicas e hidráulicas, instalações para atendimento de 
paciente, áreas destinadas à alimentação e ao lazer dos pacientes, serviços gerais e especializados, detalhes sobre tipos de materiais, sistema de segurança contra acidentes e de emergência, instalações e destinos adequados de dejetos, finalizando com pormenores, recomendando que fossem atendidas as peculiaridades, necessidades locais e condições específicas de cada caso.

Sobre o item "serviços gerais e especializados", ainda na parte B, a enfermagem teve destaque com espaços destinados à chefia de enfermagem, seus anexos, como sanitário e secretaria, no que se referia à unidade de administração, compondo cerca de 12 a $24 \mathrm{~m}^{2}$ no total, variando com o porte do hospital. Nos demais espaços, tais como unidade de internação, berçário, pediatria, tratamento intensivo, emergência, centro cirúrgico e centro obstétrico, o posto de enfermagem foi citado como devendo estar em posição central e a até 35 metros, no máximo, do quarto mais distante, e com metragem entre 4 a $12 \mathrm{~m}^{2}$, dependendo da unidade e do tipo de hospital (Brasil, 1977). Esse espaço foi mais bem descrito no Manual de Orientação "Construções e Instalações de Serviços de Saúde", que foi desenvolvido um ano após, em 1978, com o intuito de facilitar a comunicação no sistema de saúde. Nesse documento, a enfermagem era descrita como um serviço de apoio muito importante para o trabalho, não somente pelo volume, mas pela necessidade de supervisão eficiente dos membros da equipe. O posto de enfermagem, ainda nesse manual, "deveria se localizar adequadamente para que o trabalho fosse mais eficiente e menos cansativo" (Brasil, 1978).

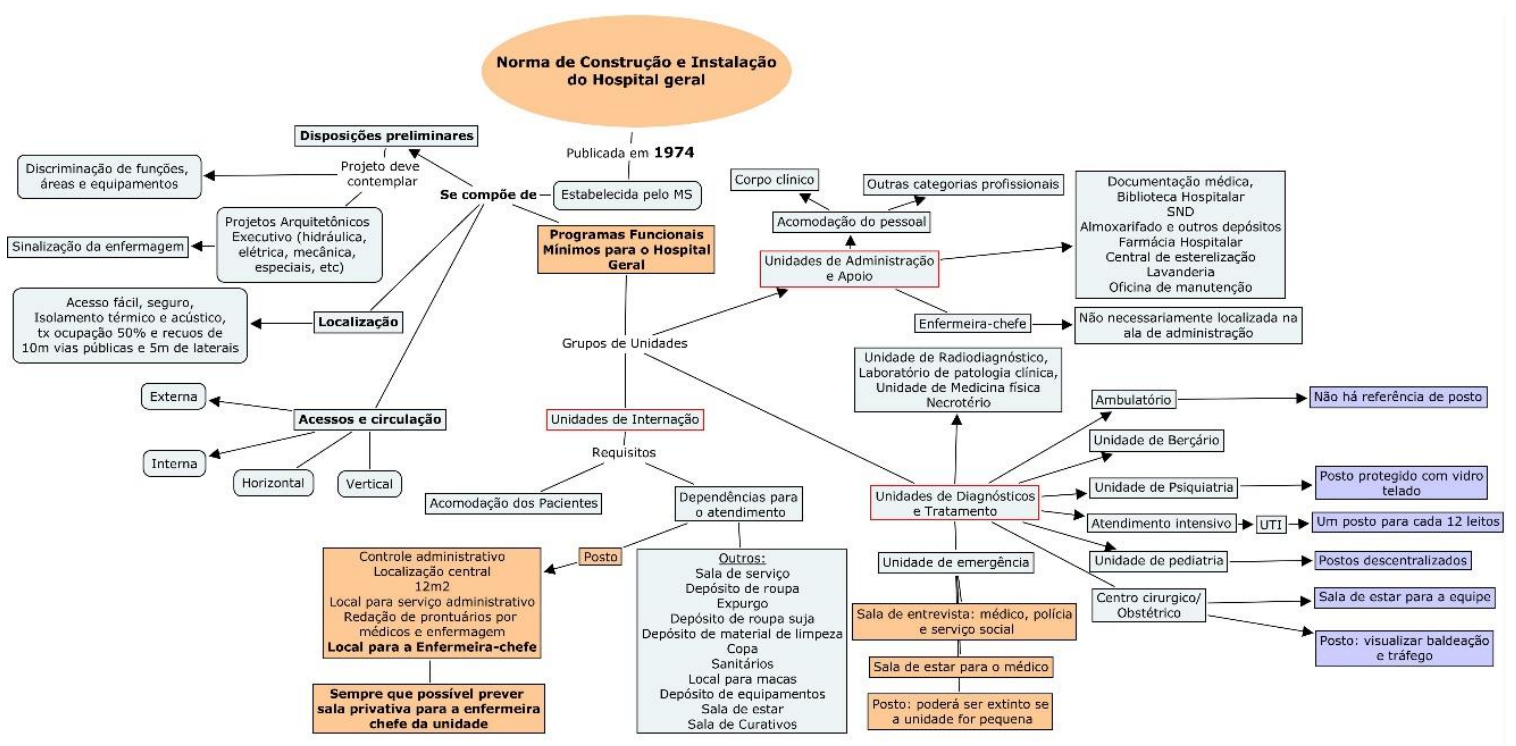

Não inclui Unidades de Saúde e destaca em laranja os "espaços da enfermagem"

Figura 2. "Normas de Construção e Instalações do Hospital Geral", "Normas de Administração e Controle do Hospital".

Cinco anos depois, em 1983 foi publicada a terceira versão da norma para construção de EAS, denominada Normas e Padrões de Construção e 
Instalações de Serviços de Saúde. Essa norma não destaca individualmente o grupo de trabalho que a construiu e sim o Ministério da Saúde. Seu objetivo era agregar conteúdo que colaborassem com a adequação física e funcionalidade de EAS no país. Essa versão fundamentou-se na Resolução da Comissão Interministerial de Planejamento e Coordenação das Ações de Saúde (CIPLAN) no $3 / 80$, estabelecendo condições para a expansão e adequação da rede de serviços de saúde, incluindo tipologia física e dotação de pessoal. Além disso, diferente da anterior, nessa norma foi incluído o manual de orientação, constituindo um de seus capítulos, o que na versão anterior era um documento separado (Brasil, 1983).

A estrutura de conteúdo desse documento muito se assemelhava aos anteriores, como pode ser observado na Figura 3, ou seja, apresentava divisão em três partes, sendo A - conceitos e definições; B - hospital geral de pequeno e médio porte e $\mathrm{C}$ - unidade sanitária. No que se refere às mudanças, observou-se a inserção do conceito de posto de enfermagem como sendo um elemento destinado a atividades administrativas do serviço de enfermagem. Assim, para o preparo de medicação e do material utilizado na assistência do paciente, foram concebidos outros espaços - a sala de serviço que, nas sugestões de planta física constantes do documento, viria acoplada ao posto de enfermagem. Sobre a metragem desses espaços, cabe ressaltar que houve manutenção das medidas, que variavam entre 4 a $12 \mathrm{~m}^{2}$, dependendo do porte do hospital e das características da unidade. Já no item $C$ da referida norma, há que se mencionar que houve decréscimo do espaço destinado à sala de atendimento de enfermagem em centros de saúde que, na norma anterior, era sugerida com a metragem de $9 \mathrm{~m}^{2}$. Nessa e nas normas anteriores, o serviço de apoio previa espaço físico para direção de serviços de enfermagem, a ser localizado no setor administrativo (BRASIL, 1983). Observou-se ainda sugestão de mobiliário mais numeroso para apoio e supervisão dos serviços de enfermagem, com relação a norma anterior (Brasil, 1977).

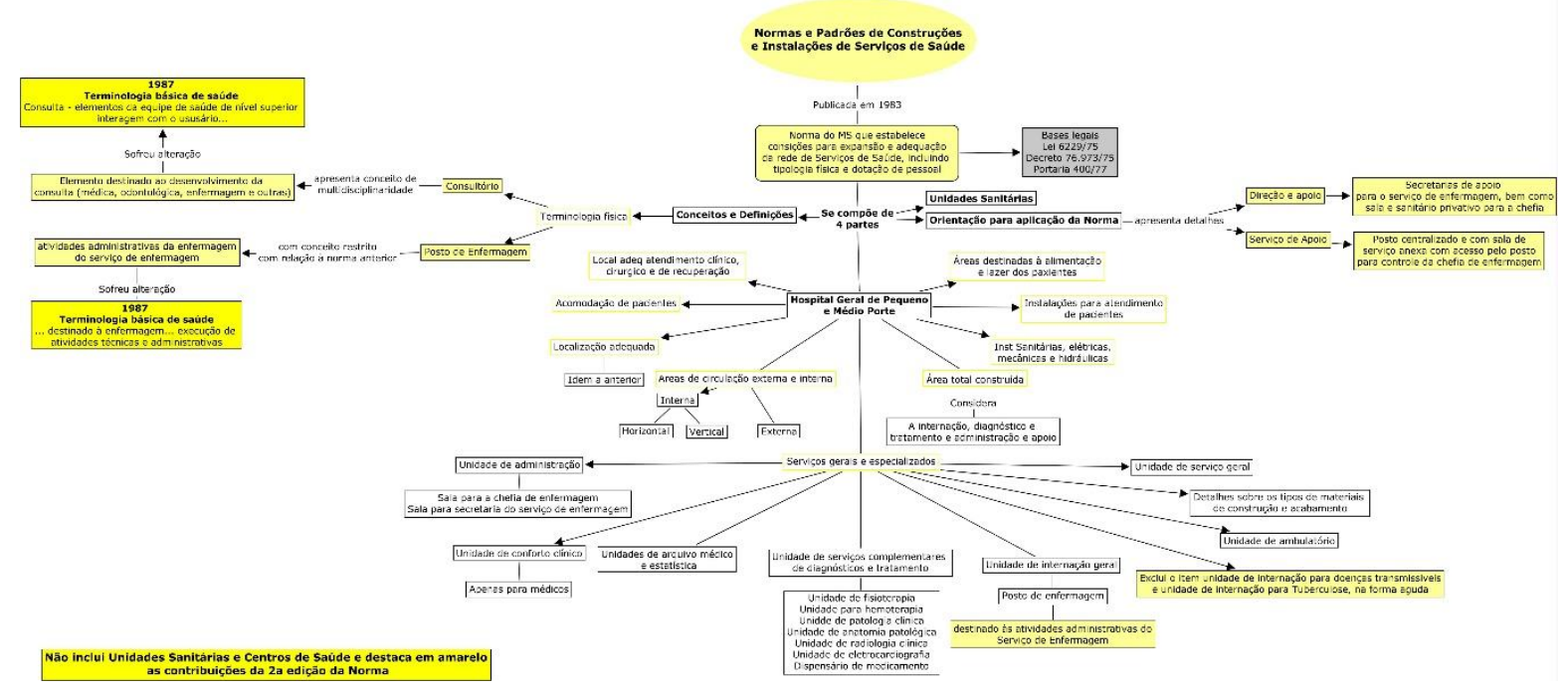

Figura 3. Normas e Padrões de Construção e Instalações de Serviços de Saúde. 
Quatro anos após, em 1987, foi publicado o documento "Terminologia Básica em Saúde" (Brasil, 1987), instituído como elemento facilitador da comunicação no sistema de saúde e para facilitar a compreensão da norma proposta em 1983. Esse documento foi revisado e atualizado quanto aos termos, por um grupo de trabalho constituído de professores designados por diversos órgãos do Ministério da Saúde. Nele, a assistência de enfermagem foi conceituada como "modalidade de atuação realizada pela equipe de enfermagem na promoção e proteção da saúde e na recuperação e reabilitação de doentes". No item que tratava de terminologia física, a nova definição de posto de enfermagem conceituava-o como elemento destinado à enfermagem para a execução de atividades técnicas específicas e administrativas, sendo incorporada, a ele, a sala de serviços. No mais, a terceira parte desse documento apenas tratava de estatísticas de saúde, com fórmulas para cálculos diversos (Brasil, 1987).

Em 1995, profundas alterações vieram a compor a nova proposta de normatização de espaços físicos de EAS, denominada Projetos Físicos de EAS (Brasil, 1994b). A proposta desse documento iniciou-se com a denominação de EAS como sendo "qualquer edificação destinada a prestação de assistência à saúde da população que demande o acesso de pacientes, em regime de internação ou não, qualquer que seja o seu nível de complexidade". Vale ressaltar que essa norma substituiu a Portaria do MS no 400/77, estando em consonância com a Portaria MS no 1884/94. O grupo de trabalho envolveu uma sanitarista como coordenadora geral e três arquitetos; como consultores, seis arquitetos, três médicos, dois engenheiros, duas enfermeiras e um sociólogo e como colaboradores, oito arquitetos, três engenheiros, um médico, uma arquiteta, uma farmacêutica, um administrator e uma pedagoga. $O$ referido documento era composto de três partes, como pode ser apreciado na Figura 4, sendo elas: Projetos de Construção de EAS, apresentando metodologia para a elaboração de projetos para esses estabelecimentos; Programação Funcional dos Estabelecimentos Assistenciais de Saúde, apresentando ampla análise das variáveis de programação dos EAS, sua organização funcional e o dimensionamento e quantificação dos ambientes que compõem o EAS; e Critérios para Projetos de EAS, apresentando as variáveis que orientam e regulam decisões a serem tomadas nas diversas etapas de projetos, ou seja, circulação, conforto, controle de infecção hospitalar, instalações ordinárias, especiais e de segurança contra incêndio.

No capítulo 1, denominado elaboração de projetos físicos, foram apresentadas as atribuições e atividades desenvolvidas nos diversos tipos de EAS, compondo nove atividades funcionais: 1 . ações básicas de saúde, 2 . ambulatório, 3. atendimento imediato, 4. internação, 5. diagnóstico e terapia, 6 . apoio técnico, 7. ensino e pesquisa, 8. apoio administrativo e 9. apoio logístico (Brasil, 1994b).

Nessa norma, a enfermagem foi citada em cinco das nove atribuições de serviços e atividades desenvolvidas nos EAS, ou seja, em todos os espaços descritos como áreas de atendimento à saúde, sendo considerada, portanto, serviço essencial ao funcionamento de EAS (Brasil, 1998). 
Os espaços físicos destinados à enfermagem, no que se convencionou chamar de posto de enfermagem, permaneceram com a metragem sugerida na norma anterior; porém, esse compartimento sofreu alteração importante e significativa nessa norma, no que se refere a conceito, e passou a ser compreendido, desse momento em diante, como ambiente destinado "à enfermagem e/ou médicos para a execução de atividades técnicas e administrativas", ou seja, espaço que deveria ser compartilhado e não mais único da enfermagem. Nessa norma, alguns compartimentos foram descritos em um quadro de serviços com itens de espaços físicos de atendimento à saúde destinados à enfermagem: sala de preparo de paciente (com a designação - consulta de enfermagem), sala de serviços, sala de curativo, sutura e coleta de material, sala de reidratação (oral e venosa) e sala de aplicação de medicamentos. Outra observação a ser feita é que, em grande parte das atribuições de serviços e atividades desenvolvidas nos EAS, os consultórios, que antes recebiam a designação "médicos", passaram a ser designados como indiferenciados, reforçando assim a participação da equipe multiprofissional no atendimento à saúde em EAS (Bonavides, 2012).

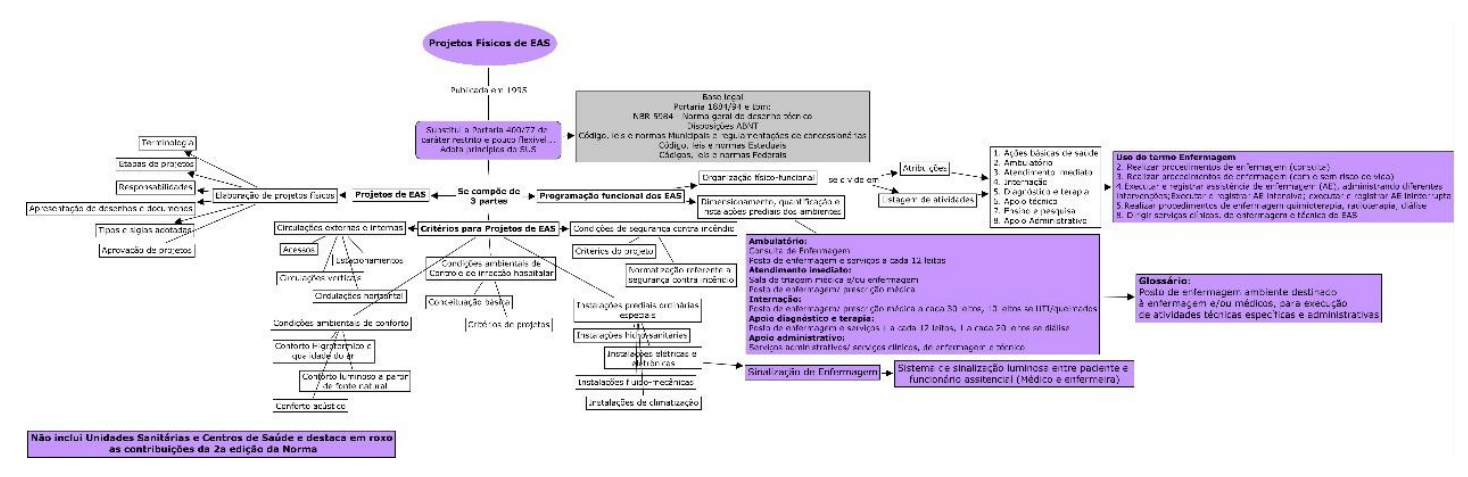

Figura 4. Projetos físicos de EAS.

Onze anos depois, em 1999, foi criada a Agencia Nacional de Vigilância Sanitária (ANVISA), com a progressão da implantação do SUS e das agências reguladoras. A ANVISA fundamenta-se no direito sanitário, exerce o controle estatal e tem, como competência, regulamentar e fiscalizar as atividades concernentes à saúde pública. Dessa forma, a normatização para projetos arquitetônicos e a rede física de assistência à saúde passaram a ficar sob sua regulação e fiscalização (Limeira, 2006). Em 2000, foi promovido um estudo pela Gerencia Geral em Tecnologia em Serviços de Saúde da ANVISA que, posteriormente, se consolidou na Resolução de Diretoria Colegiada (RDC) nº 50, de 21 de fevereiro de 2002, publicada sob a forma de Portaria, nomeada GM/MS n 554 de 19 de março de 2002, que revogou a Portaria do MS no 1884/94 (Limeira, 2006).

A RDC50 foi estruturada como essa norma, que a antecedeu, em três partes, agora denominadas: projeto de EAS; programação físico funcional dos EAS e critérios para projetos de estabelecimentos assistenciais de saúde. A Figura 5 explicita seu conteúdo, por meio de mapa conceitual. As atribuições e 
atividades desenvolvidas nos diversos tipos de EAS passaram a compor oito atividades funcionais: 1 . atendimento em regime ambulatorial e de hospital-dia, 2. atendimento imediato, 3. atendimento em regime de internação, 4 . apoio ao diagnóstico e terapia, 5 . apoio técnico, 6 . ensino e pesquisa, 7. apoio administrativo e 8. apoio logístico.

Sobre a parte III da RDC50, ou programação físico funcional, de modo geral, observou-se a padronização da metragem do posto de enfermagem em $6 \mathrm{~m}^{2}$ em média, com exceção apenas para algumas unidades como berçário e serviços diagnósticos, com $4,5 \mathrm{~m}^{2}$, e serviços administrativos de enfermagem para $12 \mathrm{~m}^{2}$, em média (LIMEIRA, 2006). Nota-se que houve grande preocupação, nesse momento, com o estabelecimento das dimensões dos elementos que compõem os compartimentos dos EAS.

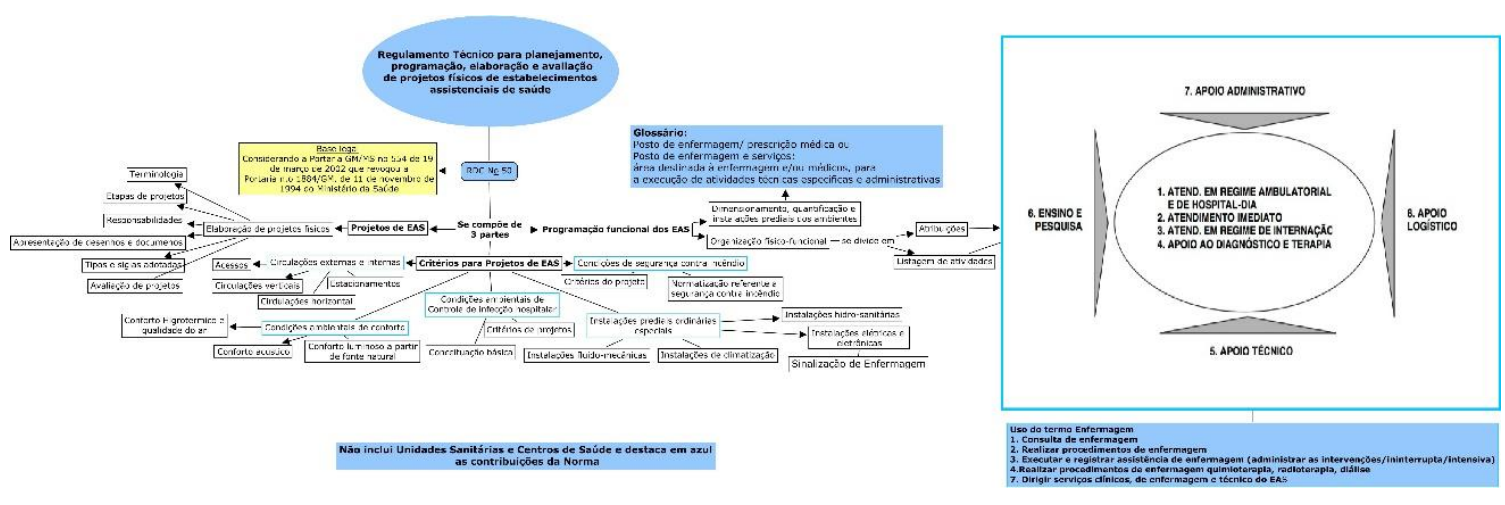

Figura 5. RDC50

\section{DISCUSSÃO}

Comparando o conteúdo da norma de 1974 com a de 1977, observou-se que havia grande diferença nas descrições de espaços entre uma e outra. A primeira apenas apresentava áreas, sem especificar detalhes sobre os profissionais que as ocupavam. A enfermagem foi citada apenas eventualmente, em espaços denominados "postos". Já a segunda norma, de 1977, era muito mais específica quanto aos profissionais que ocupavam as áreas de atendimento, dando grande destaque à enfermagem, principalmente no que se referia às áreas de internação, "sugeridas" como áreas de enfermagem. Assim, observou-se que a enfermagem, de acordo com a norma, pareceu ocupar espaços físicos definidos e obter reconhecimento de seu papel administrativo ("sala para a chefia de enfermagem") e assistencial ("unidade de enfermagem"), tendo essa ocupação sido diferenciada em termos de localização e atuação. Nessa época o movimento da reforma sanitária, que surgiu em 1970 no contexto da luta contra a ditadura, compunha um conjunto de ideias que se tinha em relação às mudanças e transformações necessárias na área da saúde. Essas mudanças não abarcavam apenas o sistema, mas todo o setor saúde, em busca da melhoria das condições de vida da população. Profissionais da saúde preocupados com a saúde pública desenvolveram teses 
e integraram discussões políticas, como a elaboração das normas para construção e reforma de EAS (Paiva e Teixeira, 2014).

Na norma criada em 1983, foi possível observar a manutenção dos espaços destinados à enfermagem e mais detalhamento dos serviços, com ênfase no investimento de pessoal de apoio e espaço para acomodação de pessoal para realizar os serviços de enfermagem com mais qualidade. Além disso, a análise dessa norma permitiu concluir também que os espaços foram delimitados ainda mais e o conceito de multidisciplinaridade foi incorporado ao espaço físico, ou seja, as atividades administrativas foram alocadas no setor administrativo e, no setor assistencial, foram descritas como áreas diferentes, com atividade laboral diferenciada, a segunda incluindo mais um espaço para serviços de apoio. A análise dessa norma permitiu considerar que a enfermeira passou a disputar o espaço dito privativo com o profissional médico.

Considerando que a norma é a expressão do acordo social em consequência de disputas de espaços, nesse caso, pode-se afirmar que a enfermagem cedeu espaço influenciada pelo contexto social, político e econômico do País. Nesse período, as políticas norteadoras do setor saúde no Brasil sofreram influência direta das políticas públicas mais abrangentes. O modelo assistencial orientouse para o mercado de compra e venda de serviços e consequente acumulação de capital, traduzido pela tecnificação dos atos médicos, enfatizando a assistência hospitalar no chamado modelo hospitalocêntrico. Paralelamente, as escolas de enfermagem viviam o paradoxo da formação fundamentada em modelos assistenciais clínico e epidemiológico. O modelo hospitalocêntrico trazia a divisão técnica e social do trabalho, com tendência à especialização, fragmentação do processo assistencial e expansão de indústrias de medicamentos, instrumentais e equipamentos e isso significava capital financeiro. O profissional médico era o profissional ideal para atender à demanda do capitalismo, justificando, assim, o modelo assistencialista focado na cura, tendo o hospital como o centro da ação assistencial de saúde (Ciampone e Kurcgant, 2004). De fato, o contexto da época impulsionava o destaque do profissional médico.

A partir de 1988, após a promulgação da Constituição Federal, houve novo direcionamento para a saúde. Precisamente do artigo 196 ao 200 da carta magna, figuram disposições em que a saúde passou a ser considerada como "direito de todos e dever do Estado, garantido mediante políticas sociais e econômicas que visem à redução do risco de doença e de outros agravos e ao acesso universal e igualitário às ações e serviços para sua promoção, proteção e recuperação". Os profissionais e os serviços passaram a ser fiscalizados por terceiros e as coordenadas - descentralização, integralidade e participação da comunidade, influenciaram as diretrizes para a construção de EAS. (Brasil, 1998).

Em 2001, o Ministério da Saúde instituiu um Programa Nacional de Humanização da Assistência Hospitalar - PNHAH, propondo prioritariamente mudanças nas relações entre os atores do Sistema Único de Saúde - SUS (gestores, trabalhadores e usuários), com a finalidade do fortalecimento dos princípios do SUS. Em 2003, esse programa passou a ser chamado de Política Nacional de Humanização da Atenção e Gestão em Saúde - HumanizaSus 
(Brasil, 2008). O investimento nas relações de trabalho ficou em evidência, como recurso para a boa qualidade do serviço assistencial prestado, e a multiprofissionalidade ganhou mais destaque ainda, influenciando a conformação dos espaços, consolidando-se na RDC50, que priorizou áreas destinadas à equipe multiprofissional. Assim, os espaços, de acordo com a norma, passaram a ser compartilhados por todos os profissionais, em resposta às políticas públicas de saúde (Ciampone e Kurcgant, 2004).

A enfermagem posicionou-se de forma reativa às transformações políticas na área da saúde e educação, poucas vezes assumindo papel de protagonista, mas marcou sua presença por meio da eficiência na concretização dos dispositivos legais. O paradoxo da formação, ora voltada para o modelo clínico, ora voltada para o modelo epidemiológico, e também as reformas no ensino de enfermagem e, portanto, do conteúdo sobre administração de serviços de enfermagem, contribuíram para a redefinição do perfil do profissional enfermeiro, que demonstrou, ao longo da história, a necessidade de desenvolver competências para executar a gestão de recursos físicos de EAS (Ciampone e Kurcgant, 2004).

A interpretação das normas de construção e reforma de EAS permitiu constatar que a enfermagem disputou "seus" espaços com a equipe multiprofissional e que o modelo de saúde hospitalocêntrico brasileiro e de hegemonia médica sustentada pelo capitalismo influenciou consideravelmente a distribuição das áreas físicas principalmente no Hospital.

\section{CONCLUSÃO}

Considera-se que houve grande transformação nas normas que orientaram a construção dos EAS ao longo do tempo pesquisado - 1974 a 2002. Essas transformações estiveram relacionadas, conforme identificado nos documentos, ao contexto social, político e econômico da época, consolidando a disputa entre as partes envolvidas com o assunto, naquele momento histórico. Assim, a saúde e a arquitetura foram autores de uma mesma obra: o espaço organizado segundo a razão e comandado pela ciência, na qual se percebe a valorização da participação do profissional habilitado como conhecedor da ação qualificada (Amora, 2006).

A enfermagem, na figura de enfermeiros que colaboraram com a elaboração das normas para a construção de EAS, com enfoque para a enfermeira Clarice Della Torre Ferrarini, parece ter participado proativamente dos primeiros momentos dessa história. No decorrer do tempo, percebeu-se que a equipe multiprofissional ganhou acesso a parte do espaço físico que era exclusivo da enfermagem ou do médico, atendendo, assim, à proposta da Constituição Federal, do HumanizaSUS e do contexto sócio-político e econômico do Brasil.

O exame da legislação sobre as edificações de EAS permitiu entender como as transformações desse espaço ocorreram ao longo do tempo, e o conhecimento sobre o assunto pode ajudar na compreensão de como a enfermagem se posicionou frente à perda da exclusividade do uso do espaço físico em favor do 
seu compartilhamento com outros profissionais de saúde. Dos achados também emergiram questionamentos sobre a aplicação da norma à realidade dos EAS, se indagando se houve descentralização do poder entre os atores sociais que compõem o atendimento em saúde no Brasil para além da proposta da norma, se há equivalência e proporcionalidade na ocupação dos espaços pelos profissionais de saúde e se a ocupação espacial atende ao previsto nas políticas de saúde enunciadas pelos órgãos oficiais, o que pode ensejar outras pesquisas sobre o tema.

\section{REFERÊNCIAS}

1. AMORA, Ana Maria Gadelha Albano. Resumo da tese: $O$ nacional e o moderno, arquitetura e saúde no Estado Novo nas cidades catarinenses. História, Ciências, Saúde-Manguinhos, v. 13, p. 1061-1063, 2006.

2. BONAVIDES, Paulo. Teoria geral do Estado. 9.ed. São Paulo: Malheiros, 2012. 558p.

3. BRASIL. IMPRENSA OFICIAL DO ESTADO DE SÃO PAULO. Constituição da República Federativa do Brasil. Brasília: Imprensa Oficial do Estado de São Paulo, 1998. 301p.

4. BRASIL. Lei 7.498, de 25 de junho de 1986. Dispõe sobre a Regulamentação do Exercício da Enfermagem e dá outras providências. Brasília: Ministério da Saúde; 1986. Disponível em: http://www2.camara.gov.br/internet/legislacao/legin.htm. Acesso em: 21 fev. 2017.

5. BRASIL. MINISTÉRIO DA SAÚDE. AGÊNCIA NACIONAL DE VIGILÂNCIA SANITÁRIA. Resolução RDC50, de 21 de fevereiro de 2002. Dispõe sobre regulamento técnico para planejamento, programação, avaliação, elaboração de projetos físicos de EAS. Brasília: Ministério da Saúde, 2002. Disponível em:

http://portal.anvisa.gov.br/wps/wcm/connect/ca36b200474597459fc8df3fbc4 c6735/RDC++№.+50,+DE+21+DE+FEVEREIRO+DE+2002.pdf?MOD=AJPE RES>. Acesso em: 21 jul. 2015.

6. BRASIL. MINISTÉRIO DA SAÚDE. Normas de construção e instalação do hospital geral. Rio de Janeiro: Ministério da Saúde, 1974. 147p.

7. BRASIL. MINISTÉRIO DA SAÚDE. Normas e padrões de construção e instalação de serviços de saúde. Brasilia: Ministério da Saúde, 1977. 88p.

8. BRASIL. MINISTÉRIO DA SAÚDE. Construções e instalações de serviços de saúde: manual de orientação. Brasília: Ministério da Saúde, 1978. 79 p.

9. BRASIL. MINISTÉRIO DA SAÚDE. Normas e padrões de construções e instalações de serviços de saúde. 2.ed. Brasília: Ministério da Saúde, 1983. $138 p$. 
10.BRASIL. MINISTÉRIO DA SAÚDE. Normas e padrões de construções e instalações de serviços de saúde. 2.ed. Brasília: Ministério da Saúde, 1987. $133 p$.

11.BRASIL. MINISTÉRIO DA SAÚDE. Projetos físicos de estabelecimentos assistenciais de saúde. Brasília: Ministério da Saúde, 1994. 144p.

12.BRASIL. Parecer n. 163/72, C.C.R. de Currículos, de 28 de janeiro de 1972. Dispõe sobre o currículo mínimo dos cursos de enfermagem e obstetrícia. In: BRASIL. MINISTÉRIO DA SAÚDE. FUNDAÇÃO SERVIÇOS DE SAÚDE PÚBLICA. Enfermagem, legislação e assuntos correlatos. 3.ed. Rio de Janeiro: Ministério da Saúde, 1974. p.721-724

13.BRASIL. Portaria n. 1721, de 15 de dezembro de 1994. Fixa os conteúdos mínimos e duração do curso de graduação em enfermagem. Diário Oficial da República Federativa do Brasil, Brasília, Seção 1, p. 19801-19802, 16 dez. 1994.

14.BRASIL. MINISTÉRIO DA EDUCAÇÃO. SECRETARIA DE EDUCAÇÃO SUPERIOR. DEPARTAMENTO DE POLÍTICAS DE ENSINO SUPERIOR. COMISSÃO DE ESPECIALISTAS DE ENSINO DE ENFERMAGEM.

Portaria n. 1.518, de 14 de junho de 2000. Curso de graduação em enfermagem: diretrizes curriculares. Brasília: Ministério da Educação, 2000. Disponível em: http://portal.mec.gov.br/sesu/arquivos/pdf/enf.pdf_Acesso em: 10 out. 2014.

15.BRASIL. MINISTÉRIO DA SAÚDE. Política Nacional de Humanização: HumanizaSus. 3.ed. Brasília: Ministério da Saúde, 2006. Disponível em: <www.saude.gov.br>. Acesso em: 10 de nov. de 2008.

16.BRASIL. MINISTÉRIO DA EDUCAÇÃO. CONSELHO NACIONAL DE EDUCAÇÃO. Parecer n. 2013/2008, de 09 de outubro de 2008. Dispõe sobre carga horária mínima e procedimentos relativos à integralização e duração dos cursos de graduação em Biomedicina, Ciências Biológicas, Educação Física, Enfermagem, Farmácia, Fisioterapia, Fonoaudiologia, Nutrição e Terapia Ocupacional, bacharelados, na modalidade presencial. Brasília: Ministério da Educação, 2008. Disponível em: <http://portal.mec.gov.br/dmdocuments/pces213_08.pdf>. Acesso em: 21 jul. 2015.

17. CIAMPONE, Maria Helena Trench; KURCGANT, Paulina. O ensino de administração em enfermagem no Brasil: o processo de construção de competências gerenciais. Revista brasileira de enfermagem, Brasília, v. 57, n. 4, p. 401-407, jul.-ago. 2004.

18. DRAGANOV, Patrícia Bover; VIEIRA, Ricardo Quintão; SANNA, Maria Cristina. Recursos físicos em ambientes hospitalares: estudos no Brasil. In: CONGRESSO BRASILEIRO PARA O DESENVOLVIMENTO DO EDIFÍCIO HOSPITALAR (CBDEH), 2014, Florianópolis. Anais... Santa Catarina: ABDEH, 2014. p. 115-9. 
19. FORMIGA, Jacinta Maria Morais; GERMANO, Raimunda Medeiros. Por dentro da história: o ensino de administração em enfermagem. Revista brasileira de enfermagem, Brasília, v. 58, n. 2, p. 222-226, mar. -abr. 2005.

20. LIMEIRA, Flávia Maroja. Arquitetura e integralidade em saúde: uma análise do sistema normativos para estabelecimentos assistenciais de saúde. $177 \mathrm{f}$. Dissertação (Mestrado em Arquitetura e Urbanismo]. Faculdade de Arquitetura e Urbanismo da Universidade de Brasília, Brasília, 2006.

21.LÜDKE, Menga; ANDRE, Marli E.D.A. Pesquisa em educação: abordagens qualitativas. São Paulo: EPU, 1986. 99p.

22. PAIVA, Carlos Henrique Assunção; TEIXEIRA, Luiz Antonio. Reforma sanitária e a criação do Sistema Único de Saúde: notas sobre contextos e autores. História, Ciências, Saúde - Manguinhos, Rio de Janeiro, v.21, n.1, jan.-mar. 2014, p.15-35.

23.POLIT, Denise F.; HUNGLER, Bernadette P. Fundamentos de pesquisa em enfermagem. Porto Alegre: Artes Médicas; 2004. 391p.

24. RICHARDSON, Roberto Jarry. Pesquisa social: métodos e técnicas. 3.ed. São Paulo: Atlas, 1999. 333p.

25. SANNA, Maria Cristina. Histórias de enfermeiras gerentes: subsídios para a compreensão de um modelo-referência de organização de serviços de enfermagem no período de 1950 a 1980. Rio de Janeiro: Escola Anna Nery/UFRJ, 2002. 167p.

26. TAVARES, Romero. Construindo Mapas Conceituais. Ciências \& Cognição, 2007, Vol 12: 72-85, 2007.

Recebido: 15 de janeiro de 2018. Publicado: 20 de fevereiro de 2018

Correspondência: patricia bover draganov. E-mail:

patricia.bover@dr9.com.br

Conflito de Interesses: os autores declararam não haver conflito de interesses. 
